\title{
Sistem Pelacak Otomatis Gerakan Benda Langit Pada Teleskop Refraktor Berbasis Mikrokontroler
}

\author{
M. Burhanuddin Latief ${ }^{1)}$, Muchlas $^{2)}$, Yudhiakto Pramudya ${ }^{3)}$ \\ ${ }^{1), 2)}$ Program Studi Teknik Elektro, Universitas Ahmad Dahlan \\ ${ }^{3)}$ Program Studi Pendidikan Fisika S2, Universitas Ahmad Dahlan \\ burhanudin_latif@ee.uad.ac.id
}

\begin{abstract}
Abstrak - Banyak aktivitas menakjubkan yang terjadi pada benda-benda langit seperti bintang, matahari dan bulan setiap waktu, sehingga para astronom tertarik untuk melakukan penelitian dengan cara melihatnya melalui teleskop. Saat ini teleskop yang tersedia sebagian besar hanya dapat melakukan pelacakan gerak bintang saja. Melalui penelitian ini, dirancang teleskop yang dapat melakukan pelacakan secara otomatis gerak matahari dan bulan. Sistem pelacak benda-benda langit pada penelitian ini dibangun dengan menggunakan motor stepper yang dikendalikan oleh mikrokontroler jenis ATMega32. Algoritma pengendaliannya menggunakan sistem kendali terbuka dengan basis waktu. Kinerja alat diuji dengan membandingkan hasil pengukuran pergeseran sudut setiap jam dari teleskop refraktor terhadap nilai teoritiknya untuk setiap benda langit yang diamati. Hasil penelitian menunjukkan bahwa sistem yang dibangun dapat melakukan pelacakan secara otomatis pergerakan benda-benda langit dengan akurat. Kelebihan dari sistem ini adalah menyediakan fasilitas setting sudut melalui tombol saklar yang disediakan tanpa melakukan program ulang. Selain itu, sistem ini menyediakan pula mode pelacakan gerak bulan secara otomatis, yang tidak tersedia pada teleskop refraktor yang lain.
\end{abstract}

Kata kunci: pelacak otomatis, benda langit, teleskop refraktor, mikrokontroler, motor stepper

\begin{abstract}
Astronomis are interested in doing research in away to see the celestial objects through a telescope . Currently most of the available telescopes only do tracking the stars. The telescope in this study can automatically tracking the motion of the sun and moon. Tracking system celestial objects in this study was built using a stepper motor controlled by a microcontroller ATMega32. Control algorithm employs a time based open control system. It's performance was tested by comparing the results of the angle shifts measurements every hour of the refractor telescope with it's teoritik values for each celestial bodies observed. The results showed that the system is able to perform automatic tracking of the celestial objects movement accurately. The advantages of this system is to provide a facility to set an angle through the key switch without reprogramming. In addition, this system also provides moon motion tracking mode automatically, which is not available on other refractor telescopes.
\end{abstract}

Key words: automatic tracking, celestial bodies, refractor telescopes, microcontroller, stepper motor

\section{PENDAHULUAN}

Tata Surya adalah kumpulan benda langit yang terdiri atas bulan, bintang, matahari dan semua objek yang terikat oleh gaya gravitasinya. Banyak aktivitas menakjubkan yang terjadi di tata surya setiap waktu, sehingga para astronom tertarik melakukan penelitian benda-benda langit dengan cara melihat melalui teleskop.

Sebagian besar industri pembuat teleskop menghasilkan alat ini hanya dapat difungsikan untuk mengamati pergerakan bintang saja secara otomatis dan belum tersedia sistem teleskop yang dapat digunakan untuk mengamati pergerakan bulan secara otomatis. Sedangkan kebutuhan pengamatan terhadap bulan oleh para astronom maupun kalangan akademisi semakin meningkat, mengingat objek bulan merupakan salah satu objek menarik bagi peneliti bidang astronomi. Oleh karenanya diperlukan sistem kendali otomatis pada teleskop untuk mengamati pergerakan bulan dan bendabenda langit lainnya.

Upaya tersebut dimungkinkan dengan adanya perkembangan teknologi motor stepper yang dapat digunakan untuk menggerakkan suatu benda secara terprogram. Dari sinilah muncul pemikiran untuk memanfaatkan sistem kendali motor stepper yang berfungsi untuk menggerakkan teleskop sehingga dapat mengikuti pergerakan bulan dan bintang dengan menggunakan program CodeVisionAVR berbasis mikrokontroler ATMega32.

\section{LANDASAN TEORI}

Teleskop merupakan salah satu alat yang dapat digunakan untuk melihat benda pada jarak jauh. Terdapat tiga jenis teleskop optik yang banyak digunakan saat ini, yaitu teleskop refraktor, teleskop reflektor, dan teleskop katadioptrik. Pada penelitian ini teleskop yang digunakan adalah teleskop refraktor. Refraktor atau dioptrik adalah jenis teleskop yang hanya menggunakan lensa untuk menampilkan bayangan benda.

Bumi berputar $360^{\circ}$ tiap 24 jam, sehingga untuk mengetahui pergeseran bulan, bintang, dan matahari dapat dilihat dalam Tabel 1. 
Tabel 1. Perhitungan Pergeseran Sudut Per Jam [1].

\begin{tabular}{llccc}
\hline No & Nama Objek & $\begin{array}{c}\text { 1 Putaran } \\
\text { bumi }\end{array}$ & $\begin{array}{c}\text { Waktu } \\
\text { (jam) }\end{array}$ & $\begin{array}{c}\text { Sudut } \\
\text { (per jam) }\end{array}$ \\
\hline 1 & Bulan & $360^{\circ}$ & 24,81 & $14,51^{\circ}$ \\
2 & Bintang & $360^{\circ}$ & 23,93 & $15,04^{\circ}$ \\
3 & Matahari & $360^{\circ}$ & 23,93 & $15,04^{\circ}$ \\
\hline
\end{tabular}

\section{METODE PENELITIAN/EKSPERIMEN}

Penelitian ini akan membahas mengenai perancangan sistem kendali otomatis pada teleskop menggunakan motor stepper untuk menggerakan teleskop saat mengamati benda-benda langit.

Desain sistem kontrol teleskop yang akan dirancang memiliki 2 buah saklar, 6 buah switch, dan ditambah LCD untuk tampilan yang sedang diamati dan untuk mengatur nilai derajat yang akan dimasukkan. Untuk lebih jelasnya desain sistem kontrol teleskop dapat dilihat pada Gambar 1. Cara kerja sistem kontrol teleskop adalah:

1. Saklar ON/OFF digunakan untuk menyalakan dan mematikan sistem kontrol teleskop, saat sistem kontrol dalam posisi ON maka akan tertampil tulisan "Welcome" dan "Pilih Track".

2. Saklar putar digunakan untuk memilih putaran motor stepper, dan pada saat teleskop menghadap ke timur berarti saklar diposisi ke atas sedangkan saat teleskop menghadap ke barat berarti saklar diposisikan ke bawah.

3. Switch 1 digunakan untuk mengamati pergerakan matahari.

4. Switch 2 digunakan untuk mengamati pergerakan bintang.

5. Switch 3 digunakan untuk mengamati pergerakan bulan.

6. Switch 4 digunakan untuk close/keluar.

7. Switch 5 digunakan untuk menguji perputaran $360^{\circ}$ gear besar pada mounting (teleskop berputar $2^{\circ}$ ).

8. Switch 6 digunakan untuk setting, saat switch 6 ditekan maka akan tertampil tulisan setting moon, setting star, dan setting sun. Untuk memilih setting mana yang akan diganti, maka gunakan switch 2 untuk ke atas dan switch 5 untuk ke bawah. Setelah selesai menentukan setting, maka langsung tekan switch 6 untuk masuk ke nilai derajat yang akan diubah dan LCD akan menampilkan tulisan "Derajat Matahari" dengan derajat " 15,00 ". Sedangkan untuk mengganti nilai derajatnya maka tekan switch 1 untuk menaikan nilai bulat, dan switch 3 untuk menurunkan nilai bulat. Apabila ada nilai komanya maka tekan switch 2 untuk menaikkan nilai komanya dan switch 5 untuk menurunkan nilai komanya. Setelah nilai derajatnya sudah sesuai dengan yang diinginkan maka tekan switch 6 untuk menyimpan nilai tersebut di dalam mikrokontroler ATMega32.

9. Setelah setting selesai maka tekan switch 4 untuk keluar dan kembali ketampilan "Pilih Track" pada LCD, kemudian tekan switch 1, 2, atau 3 yang sesuai dengan objek yang akan diamati.
Sebelum memulai membuat suatu program yang nyata, langkah awal yang dilakukan adalah membuat alur program (flowchat) yang ditunjukkan pada Gambar 2.

Teleskop bergerak setiap 1 menit sehingga pergerakan teleskop dapat berputar lebih halus dan nilai data step yang dimasukan ke dalam program adalah pergerakan bulan 906,8 step/menit, pergerakan bintang 940 step/menit, dan pergerakan matahari 940 step/menit. Sedangkan nilai maksimal sudut yang dimasukan kedalam setting program adalah $40 \% \mathrm{jam}$, karena nilai maksimal data step adalah 2500 step/menit.

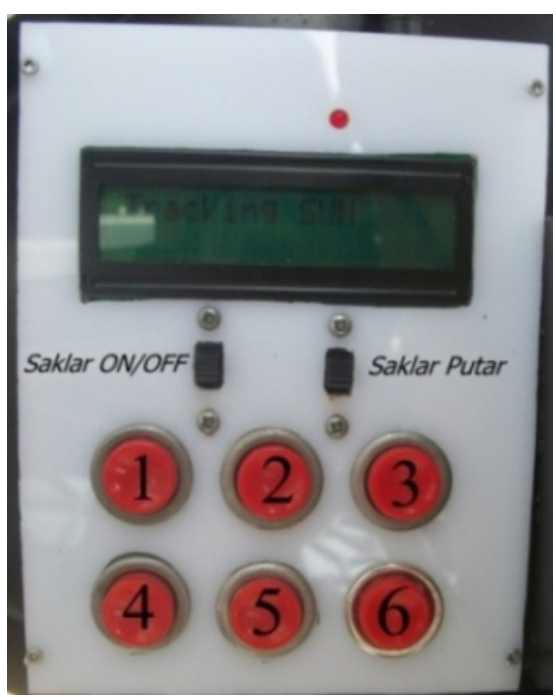

Gambar 1. Desain sistem kontrol teleskop.

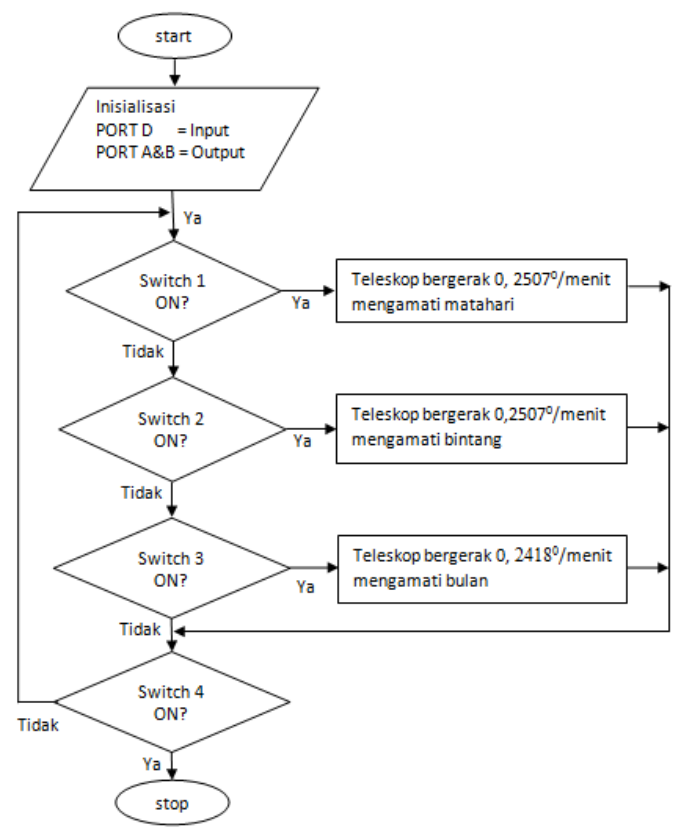

Gambar 2. Flowchart sistem kendali pergerakan teleskop. 


\section{HASIL DAN PEMBAHASAN}

Pada bab ini akan diuraikan hasil dan pembahasan terhadap proses perancangan dan hasil pengujian dari sistem yang telah dilakukan.

\section{A. Pengujian Sistem Kontrol Teleskop}

Pengujian sistem kontrol teleskop dilakukan dengan menampilkan hasil pelacakan pergerakan objek dengan pembacaan nilai sudut jam atau Right Ascension (RA) pada mounting. Sehingga untuk mengetahui perputaran bulan, bintang, dan matahari per jamnya dapat dilihat melalui nilai RA nya. Bentuk RA pada mounting dapat dilihat pada Gambar 3. Nilai RA ini dibuat 24 jam dengan pembagian perjamnya ada 6 garis, jadi tiap satu garis bernilai 10 menit dengan putaran teleskop sebesar $2,5^{\circ}$.

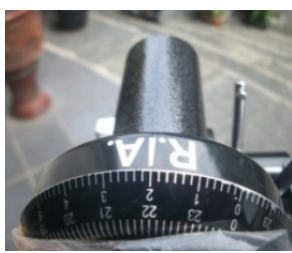

Gambar 3. Sudut jam (RA).

\section{B. Pengujian Sistem Kontrol pada Matahari}

Pengujian ini untuk mengamati pergerakan matahari dengan sudut $15,04 \%$ jam putaran teleskop. Dengan menekan tombol switch 1 maka motor stepper akan berjalan 940 step/menit. Sebelum menekan tombol switch terlebih dahulu mengatur posisi awal nilai RA seperti pada Gambar 4.

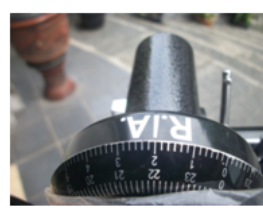

a b

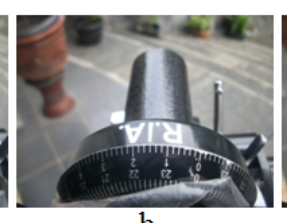

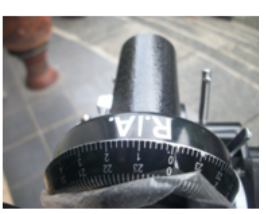

Gambar 4. Nilai RA Mengamati Matahari.

Nilai RA pada Gambar 4a diatur pada sudut putar awal, kemudian Gambar $4 \mathrm{~b}$ adalah sudut putar RA setelah 0,5 jam kemudian Gambar 4c adalah sudut putar RA setelah 1 jam. Sehingga pengamatan matahari ini sesuai dengan sudut $15,04 \%$ jam. Sedangkan untuk hasil pengamatan matahari bisa dilihat pada Gambar 5.

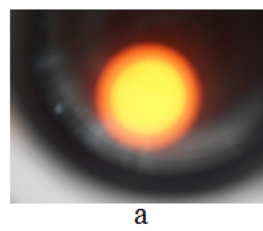

a

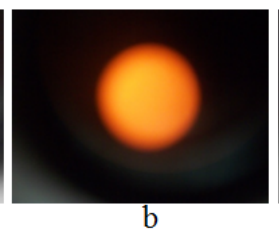

b

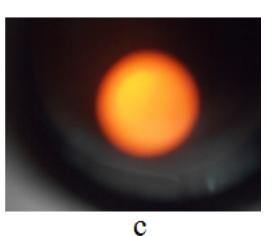

c
Gambar 5. Hasil Pengamatan Matahari.
Gambar 5a adalah posisi awal matahari, kemudian Gambar 5b adalah posisi matahari setelah 0,5 jam, dan Gambar 5c adalah posisi matahari setelah 1 jam. Dari hasil pengamatan matahari dapat disimpulkan bahwa sistem kontrol ini bekerja dengan baik karena objek matahari masih tetap berada pada titik awal pengamatan teleskop.

\section{Pengujian Sistem Kontrol pada Bintang Betelguese}

Pengujian ini untuk mengamati pergerakan bintang dengan sudut $15,04 \%$ jam putaran teleskop. Dengan menekan tombol switch 2 maka motor stepper akan berjalan 940 step/menit. Sebelum menekan tombol switch terlebih dahulu mengatur posisi awal nilai RA seperti pada Gambar 6.
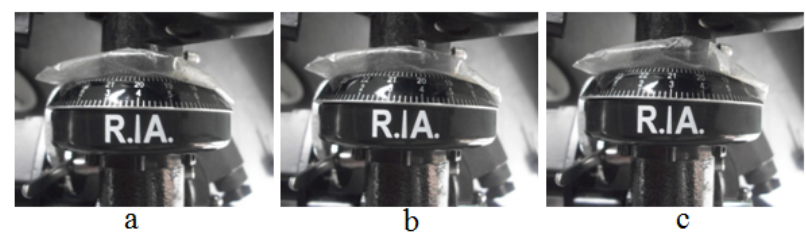

Gambar 6. Nilai RA Mengamati Bintang.

Nilai RA pada Gambar 6a diatur pada sudut putar awal, kemudian Gambar $6 \mathrm{~b}$ adalah sudut putar RA setelah 0,5 jam kemudian Gambar $6 \mathrm{c}$ adalah sudut putar RA setelah 1 jam. Sehingga pengamatan bintang ini sesuai dengan sudut $15,04^{\circ} / \mathrm{jam}$. Sedangkan untuk hasil pengamatan bintang bisa dilihat pada Gambar 7 .

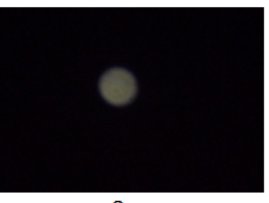

a

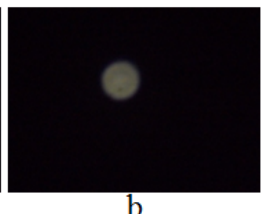

b

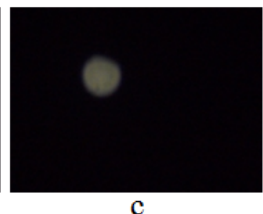

c
Gambar 7. Hasil Pengamatan Bintang.

Gambar 7a adalah posisi awal bintang, kemudian Gambar $7 \mathrm{~b}$ adalah posisi bintang setelah 0,5 jam, dan Gambar 7c adalah posisi bintang setelah 1 jam. Dari hasil pengamatan bintang dapat disimpulkan bahwa sistem kontrol ini bekerja dengan baik karena objek bintang masih berada pada titik pengamatan teleskop. Hasil gambar yang diambil tidak menggunakan titik fokus karena saat melakukan pengambilan gambar menggunakan titik fokus hasilnya tidak bagus dikarenakan saat mengambil gambar kameranya selalu bergerak.

\section{Pengujian sistem kontrol pada bulan}

Pengujian ini untuk mengamati pergerakan bulan dengan sudut 14,81\% jam putaran teleskop. Dengan menekan tombol switch 3 maka motor stepper akan berjalan 906,8 step/menit. Sebelum menekan tombol switch terlebih dahulu mengatur posisi awal nilai RA seperti pada Gambar 8. 

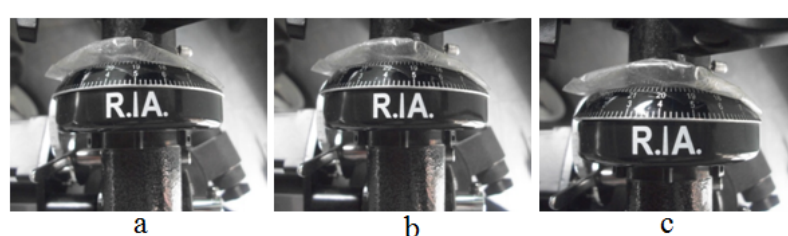

Gambar 8. Nilai RA Mengamati Bulan.

Nilai RA pada Gambar 8a diatur pada sudut putar awal, kemudian Gambar 8b adalah sudut putar RA setelah 0,5 jam kemudian Gambar 8c adalah sudut putar RA setelah 1 jam. Sehingga pengamatan bulan ini sesuai dengan sudut 14,81\% jam. Sedangkan untuk hasil pengamatan bulan bisa dilihat pada Gambar 9 .

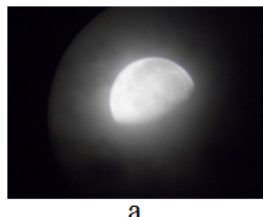

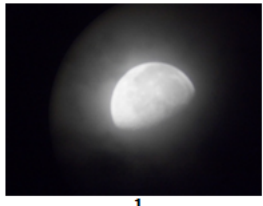

$\mathrm{b}$

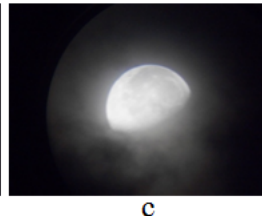

Gambar 9. Hasil Pengamatan Bulan.

Gambar 9a adalah posisi awal bulan, kemudian Gambar 9b adalah posisi bulan setelah 0,5 jam, dan Gambar 9c adalah posisi bulan setelah 1 jam. Dari hasil pengamatan bulan dapat disimpulkan bahwa sistem kontrol ini bekerja dengan baik karena objek bulan masih tetap berada pada titik awal pengamatan teleskop.

\section{E. Hasil Pengamatan Pergerakan Sudut RA}

Kinerja alat ini diuji dengan membandingkan hasil pengamatan pergeseran sudut setiap jam (RA) teleskop terhadap nilai teoretiknya, seperti terlihat pada Tabel 2 .

Penelitian ini menghasilkan bahwa pengamatan pergerakan sudut RA diatas dapat bekerja dengan baik, karena nilai RA pada teleskop sama dengan nilai teoritiknya yaitu dengan nilai akurasi $100 \%$.

Tabel 2. Hasil Pengamatan Sudut Jam.

\begin{tabular}{clcc}
\hline No & $\begin{array}{r}\text { Nama } \\
\text { Objek }\end{array}$ & $\begin{array}{c}\text { Nilai teori Sudut } \\
\text { per jam }\end{array}$ & $\begin{array}{c}\text { Nilai RA } \\
\text { pada teleskop }\end{array}$ \\
\hline 1 & Bulan & $14,51^{\circ}$ & $14,51^{\circ}$ \\
2 & Bintang & $15,04^{\circ}$ & $15,04^{\circ}$ \\
3 & Matahari & $15,04^{\circ}$ & $15,04^{\circ}$ \\
\hline
\end{tabular}

\section{KESIMPULAN}

Berdasarkan hasil penelitian dan perancangan sistem, dapat ditarik kesimpulan yaitu sistem kontrol yang dibangun pada minisistem mikrokontroler ATMega32 mampu melakukan setting program tanpa menggunakan downloader untuk mengunduh ulang program.

Selain itu sistem kontrol yang dibangun ini dapat bekerja dengan baik, karena motor stepper mampu menggerakan teleskop sesuai dengan nilai data step yang dimasukan ke dalam mikrokontroler sehingga objek benda langit yang diamati selama 1 jam selalu berada pada titik awal pengamatan.

\section{PUSTAKA}

[1] I. Morison, Introduction to Astronomy and Cosmology". Jurnal dipublikasikan. Inggris: University of Manchester, UK, 2008.

[2] A. Bejo, $C$ dan AVR Rahasia Kemudahan Bahasa $C$ dalam Mikrokontroler Atmega8535. Yogyakarta: Graha Ilmu, 2008.

[3] L. Wardhana, Belajar Sendiri Mikrokontroler AVR seri ATMega32: Simulasi, Hardware dan Aplikasi. Yogyakarta: Andi Offset, 2006.

[4] S. Nurcahyo, Aplikasi dan Teknik Pemrograman Mikrokontroller AVR Atmel. Yogyakarta: Andi, 2012.

[5] A. Winoto, Mikrokontroler AVR Atmega8/16/32/8535 dan Pemrogramannya dengan Bahasa $C$ pada WinAVR. Bandung: Informatika, 2008.

[6] E. Hadi, Mengenal Jenis-jenis Teleskop, 2011. Diperoleh dari: http://www.kafeastronomi.com/ mengenal jenis-jenis teleskop.html. (Diakses 20 Desember 2012).

[7] G. Andika, Sejarah Teleskop, 2011. Diperoleh dari: http://worldofhistories.-blogspot.com/2011/09/sejarahteleskop.html. (Diakses 20 Desember 2012).

\section{TANYA JAWAB}

\section{Bambang H., LIPI}

? Bagaimana prinsip kerja dalam mendeteksi benda yang bergerak bagaimana sistem tahu benda tersebut bergerak?

\section{Burhanuddin Latief, UAD}

@ Prinsip kerjanya adalah dengan mengirim data step pada motor steper. Dengan mengirim data stepper /menit yang ada pada mikrokontroler ATMega32, sehingga saat data sudah dikirim ke motor stepper maka motor stepper berputar dan teleskop bergerak per menitnya, sistem tahu benda bergerak adalah dari hasil pengamatannya, karena objek selalu terdeteksi di tengah teleskop saat melakukan pengamatan selama 1 jam. 